\title{
Movement and egg laying in Monarchs: To move or not to move, that is the equation 1 .
}

\author{
M.P. Zalucki ${ }^{\mathrm{a} *}$, H. Parry ${ }^{\mathrm{b}}$, J.M. Zalucki ${ }^{\mathrm{c}}$ \\ ${ }^{\text {a }}$ School of Biological Sciences, The University of Queensland, Brisbane, Australia, \\ 4072.

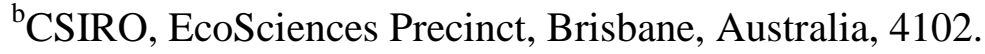 \\ ${ }^{\mathrm{c}}$ School of Environment, Griffith University, Brisbane, Australia, 4111. \\ *corresponding author: M.Zalucki@uq.edu.au
}

Monarch butterfly (Danaus plexippus) populations are in decline in agricultural landscapes, in which genetically modified crops that are resistant to herbicides (“Roundup Ready”) have resulted in the decimation of milkweed (Asclepias spp.) hosts over large areas due to the increased use of glyphosate. Movement is the key ecological process linking individual fitness traits to the utilization of sparse resources distributed across landscapes with emergent population level consequences. Often movement ecology is highly simplified or even abstracted into a simple rate of flow between populations (i.e. a metapopulation) separated by a hostile 'matrix'. Whereas, we can gain important insights into the population dynamic as a whole if we explore movement as an explicit, complex, behavioural process in which the matrix is not simply a void. We developed a spatially-explicit individual-based model to describe host seeking behaviour over the lifetime of a monarch butterfly, which utilizes hosts both aggregated in patches and scattered across the wider landscape as a substrate for laying eggs. We examine the simulated movement distances and spatial population distribution (eggs laid) as a result of different movement rules (directionality), perceptive distance (ability to find) and landscape configuration (how milkweed is distributed). This indicates the potential consequences of cleaning up the matrix (i.e. the obliteration of non-crop vegetation with Roundup) and changing habitat configurations at a landscape scale on individual movement behaviours and the emergent number of eggs laid, essentially the birth term in any population model. Our model generates movement distances of the order of $12 \mathrm{~km}$ commensurate with summer breeding monarchs and suggests milkweed removal has reduced egg laying by up to $30 \%$. We suggest possible amelioration strategies. 
Keywords: Monarch butterflies; Individual-based simulation models; Emergent processes; Host finding behaviour; Spatial ecology; Movement

\section{Introduction}

Increasingly habitats are being cleared and fragmented by anthropogenic activities. These activities, usually associated with agriculture, urbanisation, mining and so forth, directly and indirectly lead to the decline and local extinction of the less vagile species that have specialized habitat requirements (Walter \& Zalucki 1999; Sands \& New 2002). Approaches to research, conservation and management of such fragmented populations treat the ensemble of remaining habitat patches as a 'metapopulation', with the persistence of any species depending on a mixture of population dynamics within remnant habitat patches and dynamics across patches, all else being equal (e.g. Hanski 1989, 1999; Hanski et al. 1995; Hill et al. 1996). However, we consider that metapopulation concepts, which generally ignore the possibility that the area between suitable patches may be less than hostile, are limited in their ability to suggest viable options for habitat restoration beyond patch-focused recommendations and very general statements about the landscape; see also Shreeve et al. (2004). In addition Hawkes (2009) points out movement behaviours are more complex than random walk approaches when response to habitat is incorporated, and recommends the use of mechanistic, rather than phenomenological, models in description of dispersal.

In a metapopulation, a species persistence will depend on the size and spatial arrangement of the remaining habitat areas, their rates of creation and destruction, and movement amongst such habitats. The movement process is central to persistence and can be broken down into the likelihood of leaving, traversing a potentially treacherous landscape, often termed the 'matrix' (Driscoll et al. 2013), finding new areas (the search process) and utilising them (Zalucki \& Lammers 2010).

Metapopulation models do not explicitly treat the background matrix that embeds the useable habitat patches as having any suitable resources, and thus the matrix has no influence on the overall landscape ecology of the species (Wiens 1997; Turner et al. 2001; Zalucki \& Lammers 2010). Some exceptions exist, for example where the matrix in a metapopulation model has an implicit influence on colonisation or 
dispersal success as a function of distance (e.g. Drielsma \& Ferrier 2009) and ‘texture’ (e.g. Westerberg \& Wennergren 2003).

Butterflies have been used as model systems when exploring the interaction of landscape structure and population persistence. Their habitat requirements are relatively well known (Dover et al. 1997; Walter \& Zalucki 1999; Shreeve et al. 2001; Dennis et al. 2003). The assumption that butterflies do not use the space between habitats has been questioned (Dennis 2004), although how it is exploited will depend on the biology of the particular species (Dennis et al. 2004). As has been pointed out by Dennis (2004) the matrix is not a void and may variously provide suitable nectar and other resources, such as larval host plants that may be utilised.

Here we use a spatially-explicit movement model of individual monarchs to investigate the effect of both the amount and spatial arrangement of resources (patches of habitat) within a landscape on egg laying. The individual-based model of butterfly movement, habitat selection preference and oviposition behaviour was designed to allow us to explore mechanistically the impact of individual movement behaviours on emergent egg distribution in a landscape (see also Stolk et al. 2007). Our objective was to consider what happens to persistence of a species if the matrix is cleaned up and made a void, due to say herbicide usage on host plants (e.g. milkweeds) growing in agricultural fields. With Roundup Ready soybeans and corn being widely grown in the north-eastern USA such extirpation of low density milkweeds and large patches has occurred (Pleasants \& Oberhauser 2012). We created a landscape in which remnant patches of milkweed habitat may still be present in old fields, and along roadside verges, but the area in between has been made clean, a situation analogous to a classic metapopulation. We used a simulation modelling approach to explore some of the theoretical consequences of such clearing and different spatial arrangements of habitat as well as a restoration possibility. Although we had monarchs and milkweeds in mind we believe there are general inferences that can be drawn for spatially distributed insect populations, their conservation and management.

\section{Methods}

Searching, habitat and landscapes: putting the individual and mechanism back 
Background: The study system on which we based our model are monarch butterflies, Danaus plexippus, in their summer breeding season. The monarch is a highly vagile species that moves extensively amongst patches of host plants, milkweeds (almost exclusively species of Asclepias). Local adult monarch density appears to be aggregated around such patches (Zalucki \& Suzuki 1987), as in Root's resource concentration hypothesis (Root 1972). However, monarchs will also leave such areas; patch edges are effectively permeable (Zalucki \& Kitching 1982a; Ries \& Debinski 2001). The population that resides outside such habitat patches is substantial (Bull et al. 1985). Females are likely to have an average birth to death distance of about $11 \mathrm{~km}$ (Zalucki 1983), based on mark recapture studies (Zalucki \& Kitching 1985) and models of adult movement over the lifetime of a female in a landscape with a realistic encounter rate of milkweed. Away from milkweed patch habitat, host plants can be found at various low densities: the matrix is not empty (Zalucki et al. 1981). These scattered "single isolated plants” are utilised by monarchs as they traverse the landscape (Zalucki \& Kitching 1982b). Such plants can be found along roads and scattered amongst crops and other disturbed areas. Egg numbers per plant in these cases are often high and returns on eggs in terms of survival to the adult stage are better on single plants than for patch plants (Zalucki 1981a; Zalucki \& Kitching 1982abc; Zalucki \& Rochester 2004).

The individual-based model description follows the ODD (Overview, Design concepts, Details) protocol (Grimm et al. 2006; 2010). The model was written in Java, using the Repast Simphony 2.2 toolkit for agent-based modelling (North et al. 2013).

Model purpose: The simulation model was developed to simulate the response of an individual (female) monarch 'agent' to habitat availability and configuration in a landscape (both in terms of movement and egg laying decisions), which drives subsequent egg distributions. Based on what we know about monarch movement ecology and behaviours, it was designed to help us predict how the species responds to varying quantities and spatial configuration of sparse habitat in the 'matrix' that is often perceived as a void, and what the emergent consequences are at the landscape for monarch population density and distribution. 
Entities, state variables, and scales: The model consists of monarch agents within a spatial landscape which also comprises landscape patch agents. The model landscape consists of two types of 'patch": "habitat" and "matrix" (non-habitat). Suitable habitat patches for monarchs are defined as areas of dense milkweed (growing in patches of various sizes) and the immediate surrounding area of higher density milkweed (Zalucki 1986, 1993). Milkweed patches provide all the species requirements: host food plants available at high density for egg laying, nectar resources for adult feeding, basking sites and mating sites; sensu a union of required resource in the one place (Dennis et al. 2003). Such milkweed habitat is often found in old fields as part of succession (Bull et al. 1985; Suzuki \& Zalucki 1986). The matrix (i.e. the remaining area that is not habitat patches) may be empty or contain a low density of milkweed randomly distributed.

We were interested in the extreme effects of habitat availability on the monarch agents. We therefore created landscapes with a low percentage of habitat cover (1\%) or high cover (50\%). Artificial landscapes were generated following the method of Saura \& Martínez-Millán (2000) and were converted from ascii grids with a cell size of $56 \mathrm{~m}$ in a unit universe measuring $11.2 \mathrm{~km}^{2}$ to polygon shape files using ArcGIS. Extremes of habitat cover and fragmentation were used in the simulations to explore the effect of landscape configuration on the movement and oviposition behaviours of agents (Table 1). Habitats were either clustered or fragmented for the $50 \%$ cover. For the $1 \%$ cover landscapes habitats were also either clustered or fragmented, but we added the extreme of a uniform distribution (Table 1). For each of these landscape types we ran simulations with the matrix either void or with low density milkweed. The model runs on the artificial polygon landscapes (Fig. 1) and can be easily transferred to other landscapes including digitized real landscapes, simply by altering the spatial input data.

The model ran on a daily time step, with a number of sub-steps relating to movement (see below). The model landscape is a 'torus' - i.e. should an individual leave the edge of the square landscape it is calculated to reappear and continue its movement on the opposite side. 
Model parameters (Table 2) define the movement, biology and habitat use of the monarch and landscape patch agents. As several components were not known we varied these between small and large values to explore their effect on our simulations. Individual monarch agents have the state variables 'daily eggs laid' as well as 'daily distance moved', both of which accumulate each day with the processes of oviposition and movement, to a maximum (Table 2). Individuals were able to query their environment, where individual habitat patches were modelled as 'landscape' agents - the monarch agent would know the host plant preference value of the patch (landscape agent) that it was currently located within by implementing the 'WithinQuery’ Repast method, which used the GIS capabilities of Repast to query in which landscape agent the monarch agent was located. The agent was able to query which landscape agents were nearby, using the 'GeographyWithin' method with a specified perception radius, again using the GIS capabilities of Repast to query landscape agents within the perception range buffer; for more details on these methods see the Repast documentation available online and the classes in the repast.simphony.query.space.gis package.

Table 1: Spatial statistics for the landscapes derived using Patch Analyst 5.1 for ArcGIS 10 (Rempel et al. 2012). This is the order (from left to right) in which landscapes appear in the results section.

\begin{tabular}{|l|c|c|c|c|c|}
\hline & $\begin{array}{l}1 \% \\
\text { cover, } \\
\text { uniform }\end{array}$ & $\begin{array}{l}1 \% \text { cover, } \\
0.35 \text { frag }\end{array}$ & $\begin{array}{l}1 \% \text { cover, } \\
0.55 \text { frag }\end{array}$ & $\begin{array}{l}50 \% \\
\text { cover, } \\
0.35 \text { frag }\end{array}$ & $\begin{array}{l}50 \% \\
\text { cover, } \\
0.55 \text { frag }\end{array}$ \\
\hline Cover \% & 1 & 1 & 1 & 50 & 50 \\
\hline Fragmentation & uniform & $\begin{array}{l}0.35 \text { (less } \\
\text { clustered) }\end{array}$ & $\begin{array}{c}0.55 \\
\text { (more } \\
\text { clustered) }\end{array}$ & $\begin{array}{l}0.35 \text { (less } \\
\text { clustered) }\end{array}$ & $\begin{array}{l}0.55 \\
\text { (more } \\
\text { clustered) }\end{array}$ \\
\hline $\begin{array}{l}\text { Number of } \\
\text { patches: } \\
\text { habitat }\end{array}$ & 397 & 48 & 20 & 220 & 168 \\
\hline $\begin{array}{l}\text { Number of } \\
\text { patches: } \\
\text { matrix }\end{array}$ & 1 & 1 & 1 & 195 & 143 \\
\hline
\end{tabular}


Figure 1. Artificial landscapes used in the simulations (see Table 1 for descriptions and details). The dark areas are suitable habitat patches the grey is matrix.

Landscapes vary in fragmentation or degree of clustering and percentage cover from low (1\%) to high (50\%).

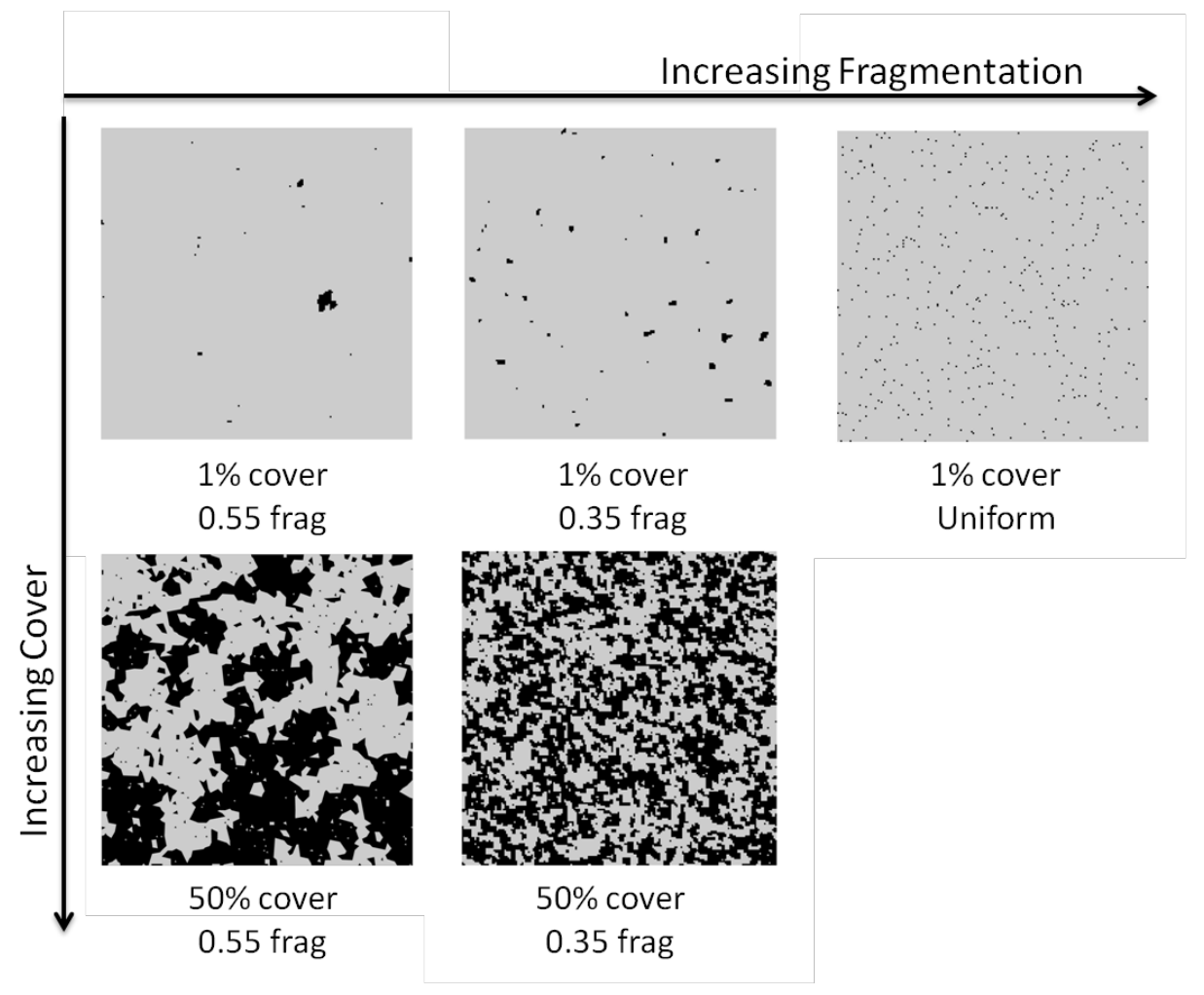


Table 2. Overview of model parameters that define movement of a monarch agent. Default values and source given.

\begin{tabular}{|c|c|c|}
\hline Parameter & Values & Source \\
\hline \multicolumn{3}{|l|}{ MOVEMENT PARAMETERS } \\
\hline Perception distance & $\begin{array}{l}5 \text { metres (short) and } 25 \\
\text { metres (long) }\end{array}$ & (Zalucki \& Kitching 1982b) \\
\hline Field of view & $\begin{array}{l} \pm 30^{\circ} \text { (narrow) and } \pm 120^{\circ} \\
\text { (wide) }\end{array}$ & $\mathrm{n} / \mathrm{a}$ \\
\hline Directionality & 0.2 (low) and 0.8 (high) & Zalucki \& Kitching (1982b) \\
\hline Step length & $\begin{array}{l}50 \text { metres (short) and } 125 \\
\text { metres (long) }\end{array}$ & $\mathrm{n} / \mathrm{a}$ \\
\hline Daily distance max & 15000 metres & $\begin{array}{l}\text { Based on the estimated limit of a } \\
\text { mark-recapture study for } \\
\text { monarchs (Zalucki \& Kitching } \\
\text { 1985) }\end{array}$ \\
\hline \multicolumn{3}{|l|}{ MONARCH AGENT PARAMETERS } \\
\hline Eggs laid per day (max) & 100 & $\begin{array}{l}\text { Based on a } 14 \text { day lifespan with a } \\
\text { total of } 1400 \text { eggs (Zalucki 1981) }\end{array}$ \\
\hline Lifespan & 14 days & (Zalucki 1981; Zalucki et al. 1986) \\
\hline Total eggs (max) & 1400 & (Zalucki 1981; Zalucki et al., 1986) \\
\hline Egg laying rate & 1 egg per 2.5 metres & (Zalucki \& Kitching 1982 ab) \\
\hline \multicolumn{3}{|l|}{ LANDSCAPE PARAMETERS } \\
\hline Percentage habitat cover & $1 \%$ and $50 \%$ & $\begin{array}{l}\text { Selected to represent extreme } \\
\text { values of lots of habitat ( } 50 \% \text { of the } \\
\text { landscape) and much reduced ( } 1 \% \\
\text { of the landscape) }\end{array}$ \\
\hline Percentage habitat fragmentation & $\begin{array}{l}0.35 \text { (fragmented), } 0.55 \\
\text { (clustered) and } 0 \text { (uniform) }\end{array}$ & $\begin{array}{l}\text { Different spatial arrangements } \\
\text { from clustered to uniform }\end{array}$ \\
\hline \multicolumn{3}{|l|}{ LANDSCAPE AGENT PARAMETERS } \\
\hline Preference value: habitat & $1.0,0.5$ and 0.1 & Arbitrary (see text) \\
\hline Preference value: matrix & 0.01 and 0 & $\begin{array}{l}\text { zero represents a clean matrix } \\
\text { and } 0.01 \text { is a matrix with randomly } \\
\text { distributed single plants }\end{array}$ \\
\hline
\end{tabular}

Process overview and scheduling: The flow diagrams (Fig. 2) detail the model processes and how they were scheduled. Model parameters defined the movement, biology and habitat use of the monarch agent. These were based on monarch butterflies (Table 2), but as many components were not known we varied these between small and large values to explore the effect on our simulations. 
Figure 2. Flow diagram of model process (egg laying and movement) and scheduling that define the movement of a monarch agent over each daily time step from birth to death.

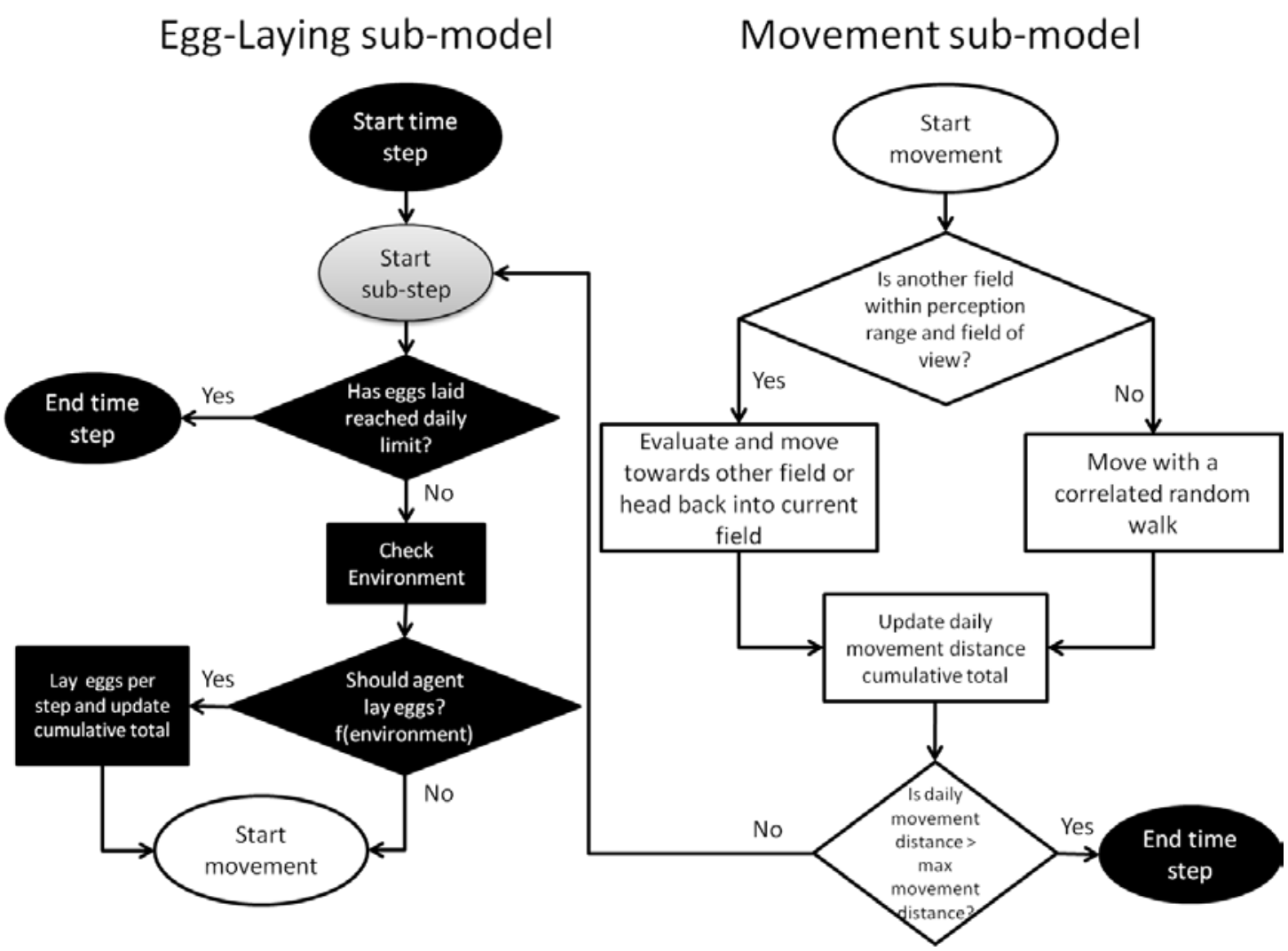

In the Egg-Laying sub-model (Fig. 2) the eggs laid per step (eggsPerStep) were a function of an estimated egg density (1 per 25 plants), where 25 plants were assumed to occupy $2.5 \mathrm{~m}$ (thus egg Density=1 per $2.5 \mathrm{~m}$ ). This was scaled to the stepSize (in m) of the movement sub-model:

$$
\text { eggsPerStep }=\text { stepSize } \times \text { eggDensity }
$$

Eq. 1

Eggs were laid at this fixed rate per movement step, however a probability based directly on the preference value of the current patch (landscape agent) that the monarch agent was within (see Table 2) determined whether the agent laid eggs during any given step.

The algorithm for movement was based on multiple movement steps within the 'daily' time step of the model. The movement steps end when the daily egg deposition limit was reached (i.e. 100) or the limit to the movement distance per time 
step was exceeded (i.e. $15 \mathrm{~km}$, see Table 2). The maximum movement distance was increasingly limited in a linear fashion each day, as the agent aged. This was an arbitrary estimate, based only on our limited knowledge of lepidopteran capacity for flight, which is known to decline over time (e.g. Sappington \& Burks 2014). The equation for the estimated decline in maximum daily distance moved is:

$$
\text { Dist }_{\max }=-1076.9 t+16077 \quad \text { Eq. } 2
$$

Where $t$ is the number of time steps (days) since the simulation began, and the lower limit for the maximum daily distance moved is estimated as $1 \mathrm{~km}$.

The preference of the current patch, relative to adjacent patches (but limited to within a perception range) influenced whether a monarch would stay within or leave the current location, and ultimately egg density (Fig. 3). The decision to stay or leave the current patch was based on the equation:

$P($ leave $)=\frac{\operatorname{Pref}_{B}}{\text { Pref }_{B}+\text { Pref }_{A}} \quad$ Eq. 3

Where $P$ (leave) is the probability that the agent will leave the current patch, $P r e f_{B}$ is the preference value for the alternate patch (within perceptive distance) and $P r e f_{A}$ is the preference value for the current patch, where small values of $\operatorname{Pref}_{B}$ are moderated in the model to allow a minimal probability of leaving even when preference is very low, so that $0.1<=P r e f_{B}<=1$. If the agent chose to move towards the alternate patch it searched within the restrictions of the perception angle to locate a direction that would take it towards the alternate patch (Fig. 3a). The agent would then move the step distance in the selected direction. If it did not choose to move towards the alternate patch and so 'returned' to the current patch, it would search with a full 180 degree perception angle and once it located a direction that would take it towards the current patch it would move towards it with the step distance in that direction. In either case, if after 100 tries the selected patch was not located then the agent would 'give up' and continue with a correlated random walk, which could happen if there was only a very small amount of the target patch within the movement range. 
The correlated random walk was calculated by modifying the current heading by a change in direction, $\theta$. This was calculated in radians as follows and then converted to degrees, with a 0.5 probability of being positive or negative (symbolised by \pm ):

$\theta= \pm \pi R(1-D) \quad$ Eq. 4

Where directionality $D$ is a variable (Table 2) and $R$ is a uniform random number between 0 and 1 (after Zalucki 1983).

Figure 3. (a) Illustration of the movement search behaviour in movement sub-model (Fig. 2). The monarch agent has a perception distance (Table 2) but the region that can be searched is restricted according to a perception angle. The agent decides whether to stay or leave the current patch (e.g. matrix) based on equation 3, and in the case that it leaves it will head towards the alternate patch (e.g. habitat) with its path restricted to the perception angle.

(b) Model graphical output showing habitats, monarch agents (little red squares) and movement pathways (in red) as well as egg density on a grey scale, the darker the colour the higher the density.

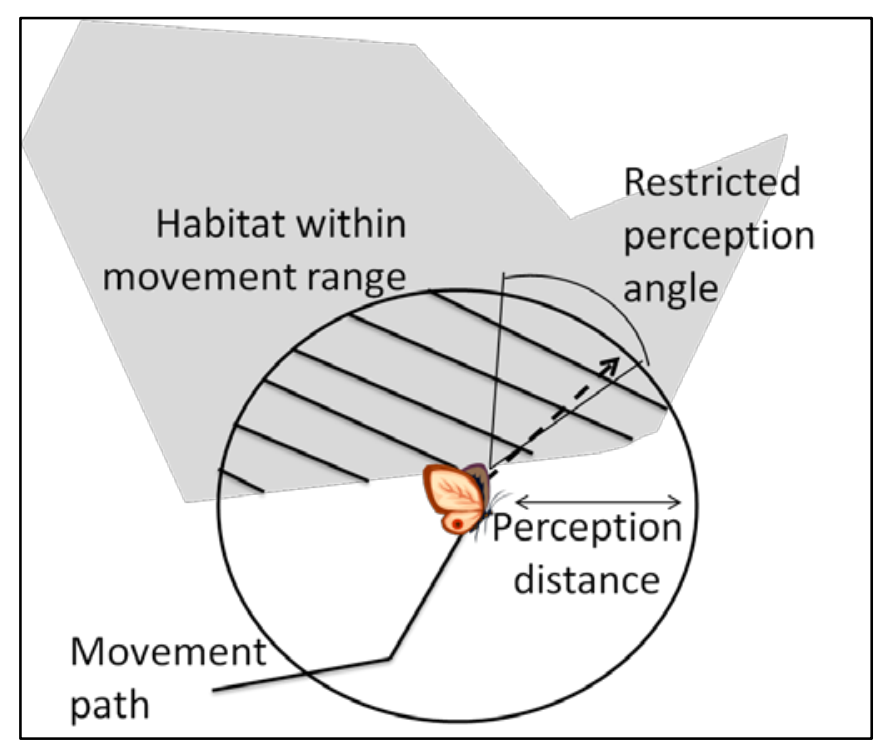

Design concepts: The model was designed to explore the influence of habitat type and configuration on the movement behaviours of monarchs. The model simulated:

- Habitat selection

- Dispersal and movement 
- Oviposition behaviours

Basic principles: The model relates to ideas of optimal foraging theory, although in this model there was no resource depletion. We simulated how an individual decides whether to stay at its current location or move on to another, in this case driven by its need to oviposit/forage in relation to its localized knowledge of the current and surrounding habitat patch quality.

Emergence: The primary results of the model, dispersal distances and egg distribution/density, emerged from the simulated movement ecology and behaviour of the individual monarch agents in relation to the habitat characteristics and spatial configuration of the landscape agents.

Adaptation: Monarch agents adapt to the landscape in terms of movement pathway and change in direction.

Objectives: The movement and foraging behaviours were implicitly fitness-seeking, i.e. assuming that the individual had an objective to maximize egg-laying/foraging within the shortest amount of time in optimal habitat.

Learning/prediction: This was not represented in the foraging model (e.g. memory of favourable habitat patches): this could be added in future versions of the model.

Sensing: Monarchs were able to query the properties of the patches in the landscape within a radius of their current location (their perception distance), within which they were assumed to have perfect knowledge of the patches/matrix location and properties.

Interaction: Agent interaction occurred when monarch agents queried landscape agents to determine the patch properties, which informed the movement rules and oviposition probability. Landscape agents also summed the number of monarch agents and the total eggs laid within their bounds each day, for output purposes. Stochasticity: The generation of the artificial landscapes was partly stochastic in terms of the placement of the patches and their size. The movement pathway and step size was primarily a correlated random walk, which was stochastic, that takes into account behavioural response to landscape. This response to landscape also had a stochastic element, where a change in direction at a boundary was probabilistic. The number of eggs laid each step was also probabilistic based on the properties of the current patch.

Collectives: There were no collectives in the model. 
Observation: Graphical output of the model showed the landscapes with habitat patches and matrix visualized in different colours (Grey scale in Fig 3b). For each individual, movement pathways were captured in the spatial model output as lines, to visualize the movement pathway results of the sub-daily steps (Fig 3b). The total daily movement distance was recorded; both direct movement distance from the initial start location to the final location, allowing for wrapping around the torus, and total movement distance over all daily steps. Egg densities were captured in the spatial output as well as a record of the total number of eggs laid in each habitat type (matrix or patch) for each step of the simulation (for each individual).

Initialization: The initial population in the model could be varied from one to tens of thousands of agents. The model was initialized using the batch run capabilities of the Repast toolkit to simulate over the entire parameter space, with a fixed number of monarch agents (100) added to the landscape at random locations for each of the five landscapes for each iteration. Each iteration of the model was run for a fixed period of 14 days (the typical lifespan of a monarch).

We used the model to address three questions:

\section{Q1: how do the matrix properties and landscape structure influence the} simulated movement behaviour of monarchs?

- We analysed the output of (lifetime) movement distance in relation to the range of simulated monarch behaviours (habitat preference, perception distance, step length and directionality) and landscape properties (\% habitat, fragmentation, quality of matrix).

Q2: what are the implications of this movement response to matrix properties and landscape structure for the distribution and total number of eggs laid?

- We analysed the output of total eggs in relation to the range of simulated monarch behaviours (habitat preference, perception distance, step length and directionality) and landscape properties (\% habitat, fragmentation, quality of matrix).

Q3: what are the implications for conservation of monarchs? We use the simulation model to evaluate a possible conservation measure 
- We compared results of the model both with and without a management scenario and quantify the benefit in terms of increased eggs laid (realised fecundity)

\section{Results}

\section{Q1 The question of scale: how far does a monarch (agent) fly?}

Of the factors tested with the simulation model, directionality and percentage habitat coverd appear to be critical to how far a monarch flies (Fig. 4). A clean matrix had a marginal effect on distance moved compared to a matrix with a low level of remnant plants; a clean matrix only adds on average $240 \mathrm{~m}$ to the birth to death distance travelled (range $0-1 \mathrm{~km}$ ) when compared to equivalent landscapes and movement parameters in the model (results not shown); as the quality of the matrix did not appear to influence movement distance greatly we present the finding for the clean matrix landscapes only (Fig. 4).

In the simulations, mean straight-line 'birth to death' distance increased with age, but the model constraint on distance flown with age (Equation 2) means that by 8 days (just over half their lifetime) agents have achieved 85\% of their total distance (results not shown). We present the total birth to death distances over 14 days below.

A few things stand out from the simulation results: (1) Lifetime 'birth to death' distances (from where an agent first starts to its position after 14 days) were short (on average 1-6 km) for landscapes with high (50\%) habitat cover (landscapes 4 \& 5 in Fig. 4) and much longer (3-18km) for those with low (1\%) cover (landscapes 1, 2 \& 3 in Fig. 4). (2) There were no other obvious differences between the major types of landscapes (1\% versus 50\% cover) in the distance moved, and (3) there were consistent effects of directionality on these distances across all landscape types. Average 'birth to death' distances (both straight-line and total) were much longer for high directionality (0.8) than low directionality (0.2) agents. These differences were greater for low \%cover landscapes (Fig. 4). 
Figure 4: Box and whiskers plot of straight-line distance $(\mathrm{km})$ from birth (location where an agent starts) to death (location after 14 days) in 5 landscape types: $1=1 \%$ cover, uniform; $2=1 \%$, fragmented; $3=1 \%$, clustered; $4=50 \%$, fragmented; $5=50 \%$, clustered (see Table 1 for details). The simulations depicted for each landscape type by directionality (0.2) and (0.8) for each step length (50m, right hand panel, $125 \mathrm{~m}$ left hand panel). (Each bar is an average over 100 (replicate) agents for each of 3 preference levels, 2 perceptive distance and 2 perception angles (700 agents total).

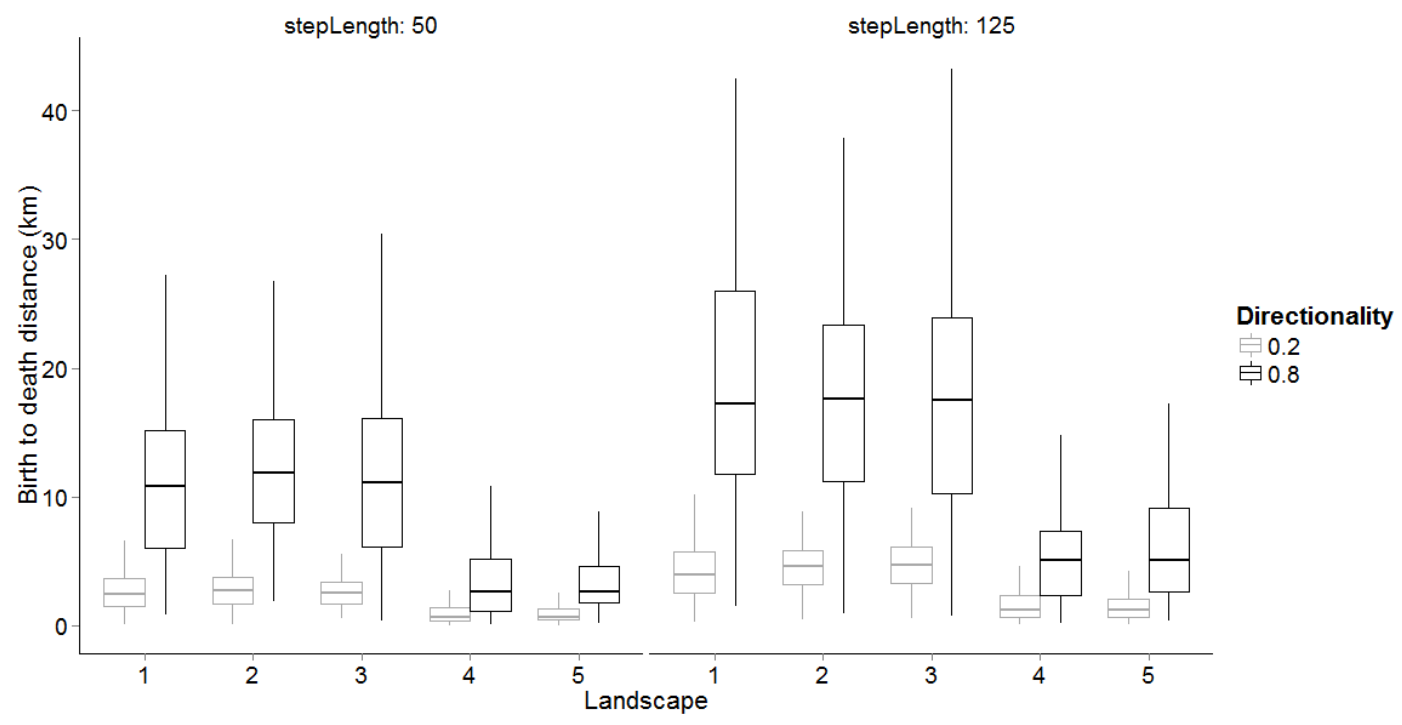

\section{Model sensitivity to step length}

The average straight-line distance moved over a life-time was consistently longer for 125m step length than 50m step length (Fig. 4). This was an artefact of the model: larger step lengths mean that monarchs travel further in a straight-line distance than shorter step lengths, when subject to the same directionality parameters. However, the relative differences between landscapes for distances moved is consistent between the two step lengths tested here. Furthermore, the step length has little effect on the number of eggs laid in each habitat type, indicating that the scaling of egg laying rate to step length in the model works well. For the equivalent set of movement parameters a larger step size (125 m) on average added only 3.4\% to the total egg lay so we present detailed results for $50 \mathrm{~m}$ step length here for effects on egg laying.

\section{Q2 Egg-laying and habitat: landscape resource distribution and the matrix}

Habitat preference, landscape and status of the matrix all had an effect on total eggs laid. Not surprisingly, high landscape cover by habitat (50\%) and the status of the 
matrix had large effects on total egg lay (Table 3). In landscapes where hosts were present in the matrix, with 50\% habitat cover monarch agents laid on average 1299 eggs (range 1075-1399), compared to an average of 612 (447-1135) eggs laid in landscapes with $1 \%$ cover. The maximum expected fecundity is 1400 eggs. The mean total eggs laid for landscapes with an empty matrix were 1274 (964-1398) and 245 (11-1034) for 50\% and 1\% cover respectively. There was a clear interaction between the effect of whether the matrix is empty or not and the percentage cover: there was little effect of an empty matrix when cover is high, but a greater effect when cover is low (Table 3). In the simulation with high cover landscapes monarch agents did well in terms of eggs laid, regardless of how they move or how resources were arranged. The effects of these other factors became more pronounced in low cover landscapes. We investigated more closely the effect of landscape structure, preference and movement for low cover landscapes below.

Except for the clustered 1\% cover landscape with a clean matrix and a low habitat preference value (0.1, highlighted in Table 3), monarch agents did much better than what would be expected by a random search model for an empty matrix situation. For the latter we would expect that agents would lay eggs in proportion to percentage cover, given they had no preference for either habitat or matrix. In our simulations they did between 1.5 and 3 times better than a random search model (Table 3).

Unsurprisingly, realised fecundity was higher in landscapes with hosts present in the matrix (compare Fig 5a and 5b). Habitat preference has a strong effect on realised life-time fecundity; as preference increases, egg number increases for each landscape type, perceptive distance and directionality (Fig 5ab). Agents had a higher propensity to leave habitat patches when there was no difference between the preferred habitat and matrix preference value (both 0.1) (Fig. 5a) and the eggs per female are low and similar for all these simulations. Monarch agents achieved higher lifetime fecundity in landscapes with a more uniform distribution of habitats (landscape 1) and there was an apparent positive effect of a greater perception distance and a smaller positive effect of directionality for all three landscapes, but it was more apparent in uniform and fragmented landscapes (Fig. 5ab). Monarch agents did least well in the model landscapes where habitat was clustered (landscape 3). 
Table 3: Mean percentage (and range) of eggs laid by 100 monarch agents out of the total possible over a life-time in each landscape type (range from smallest to largest \% eggs for all possible combination of movement parameters) by habitat preference $(0.1,0.5,1.0)$. The matrix in each landscape either contains a low background density of hosts (Matrix with hosts) or is devoid of hosts (Empty matrix).

\begin{tabular}{|c|c|c|c|c|c|}
\hline & Uniform & Fragmented & Clustered & Fragmented & Clustered \\
\hline Cover \% & 1 & 1 & 1 & 50 & 50 \\
\hline \multicolumn{7}{|c|}{ Matrix with hosts } \\
\hline Pref=0.1 & 34 & 32 & 32 & 83 & 80 \\
& $(33-35)$ & $(31-33)$ & $(32-33)$ & $(81-84)$ & $(75-81)$ \\
\hline Pref=0.5 & 54 & 44 & 37 & 99 & 97 \\
& $(43-71)$ & $(37-55)$ & $(32-40)$ & $(97-100)$ & $(95-99)$ \\
\hline Pref=1.0 & 67 & 53 & 40 & 100 & 98 \\
& $(49-87)$ & $(43-61)$ & $(34-56)$ & $(99-100)$ & $(96-100)$ \\
\hline \multicolumn{7}{|c|}{ Empty matrix } \\
\hline Pref=0.1 & 3 & 2 & 1 & 80 & 74 \\
& $(2-5)$ & $(2-3)$ & $(1-2)$ & $(78-83)$ & $(71-79)$ \\
\hline Pref=0.5 & 31 & 19 & 9 & 99 & 97 \\
& $(14-55)$ & $(10-24)$ & $(5-19)$ & $(97-100)$ & $99)$ \\
\hline Pref=1.0 & 50 & 30 & 13 & 100 & 97 \\
& $(27-85)$ & $(15-68)$ & $(5-29)$ & $(99-100)$ & $(93-100)$ \\
\hline
\end{tabular}

The distribution of eggs across the landscape (matrix or patches) reflected the presence of adults. For low values of habitat preference (0.1) and low percentage habitat cover, most eggs (and thus adults) were not in habitat units (Fig. 6); adults were essentially in the matrix. As preference increased a higher percentage of eggs (and adults) were found in habitat units in low cover landscapes, but this was much lower than the $80-100 \%$ of eggs (and adults) in high cover landscapes (Fig. 6).

Figure 5. (a) Box and whiskers plot of realised fecundity per female agent over her lifetime in three landscapes (uniform, fragmented, clustered) with a low habitat cover (1\%) for three habitat preference levels $(0.1,0.5,1.0)$ for matrix with host plants, top pair of panels (a) and empty matrix, lower pair of panels (b). Effect of perceptive distance; low (5 m) and high (25 m); shown as separate subpanels for each matrix type. Within each perception distance the effect of directionality on realised fecundity; low (0.2) and high (0.8); is shown. 

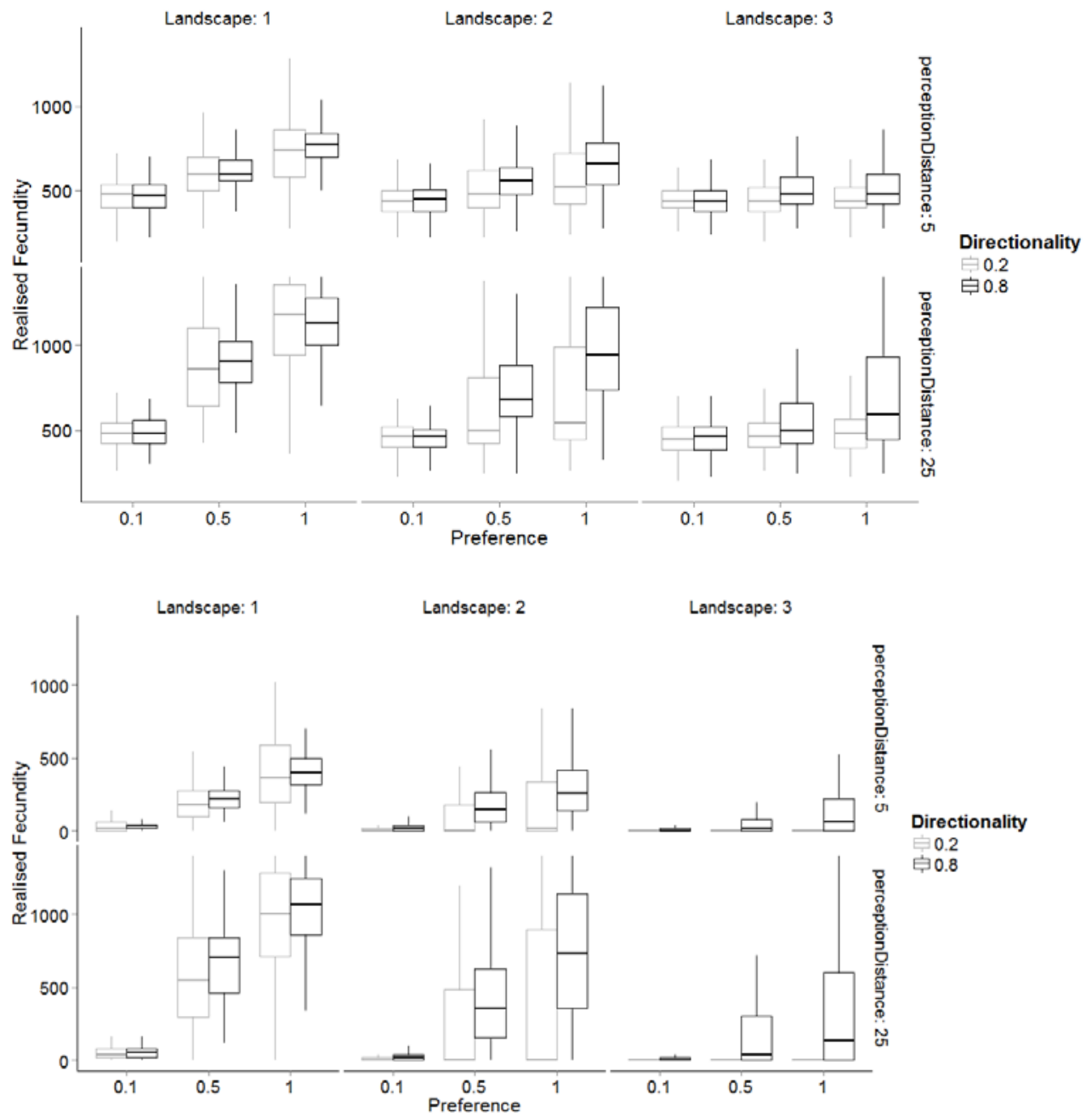

Figure 6. Box and whiskers plot of the proportion of adults in habitat units (patches) over 14 days for 5 landscape types (see Table 1 for details) and three preference values $(0.1,0.5$ and 1$)$. The variation within a landscape type reflects different perception distance and directionality effects.

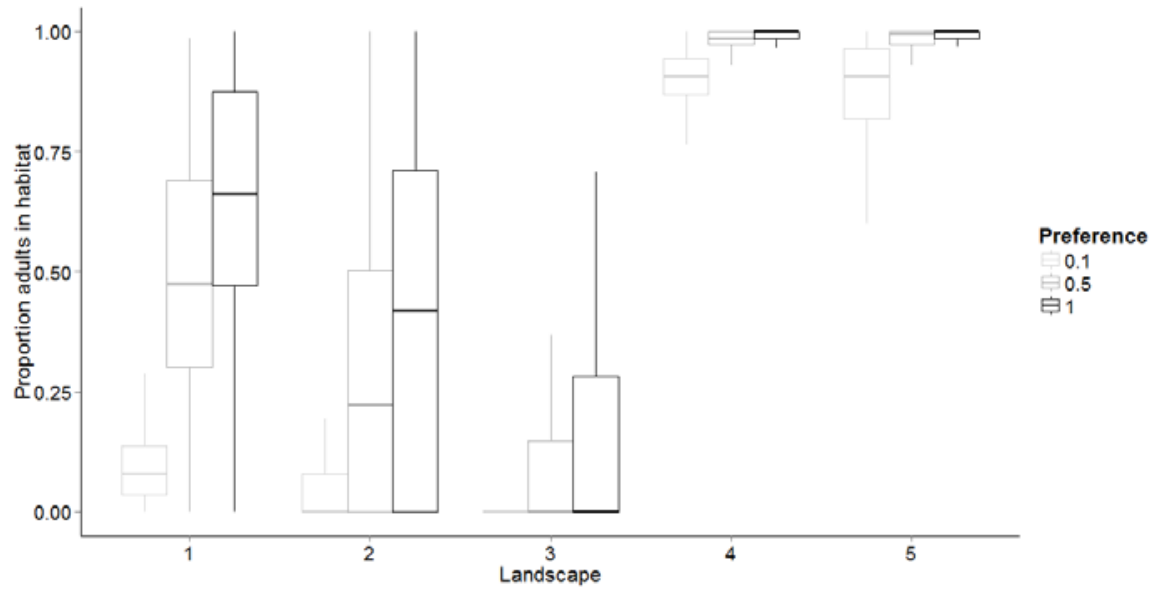




\section{Q3 Implications for monarch conservation}

It has been suggested that to help monarch populations recover, after the desolation of milkweed wrought by Roundup Ready soybean and corn and the concomitant increased use of herbicides, that milkweed be promoted along highways (Fischer et al. 2015). For the most favourable low cover landscape (uniform habitat patch distribution) with an empty matrix; analogous to Roundup Ready agriculture in the monarchs summer breeding range in North America (Pleasants \& Oberhauser 2012) we added a line of habitat down the middle to mimic the effect of a road with milkweed restored. The addition of this road habitat effectively increased cover from 1 to $2 \%$ cover. The gain in egg production averaged $51 \%$ (Fig. 7).

Figure 7. Gain in eggs for a landscape with a uniform distribution of habitat units to which a road (linear arrangement of habitat) has been added down the middle relative to a uniform landscape (landscape 1 in table 2) for three habitat preference levels. 'Gain' was always measured on comparable model configurations i.e. for the uniform vs line landscape with the same directionality, perception distance, angle, preference etc. The overall mean gain is shown (dashed line).

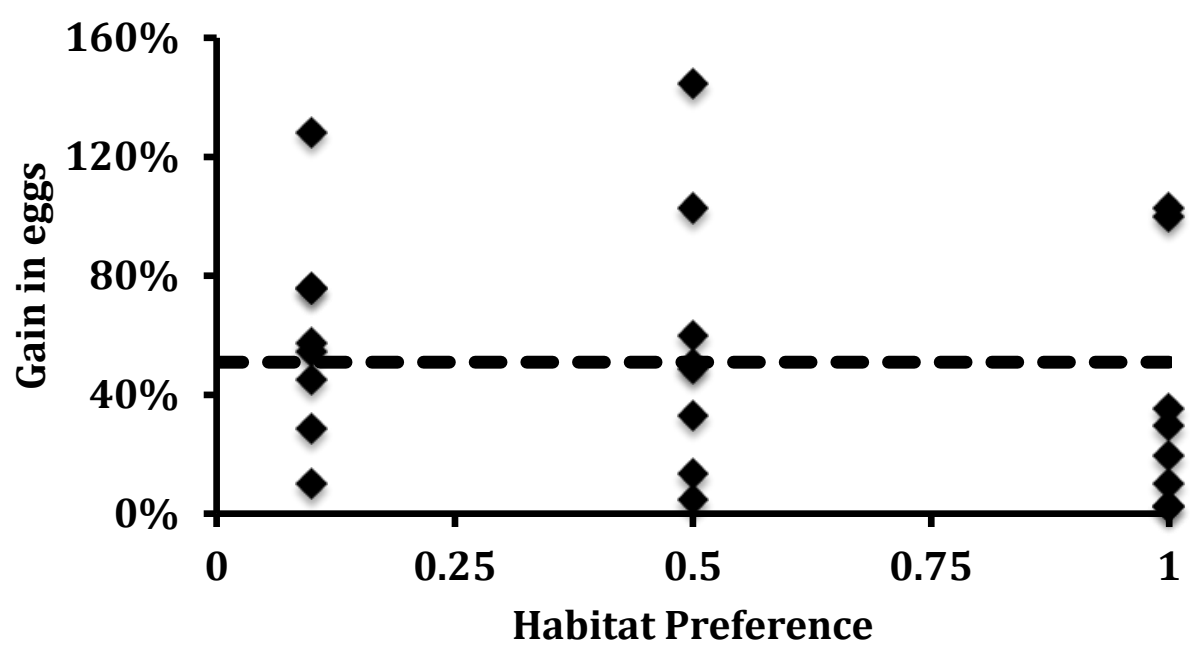

Discussion: Time, space and population dynamics revisited.

How far do insects fly? Insects, even small drosophilid, can fly a long way in inhospitable landscapes (Dickenson 2014). From our behaviour-driven simulations, long movement distances for individual monarch agents emerged under conditions of low habitat availability, particularly when habitat was clustered. This occured even when undertaking what have been described as "trivial” or foraging movements 
(Kitching \& Zalucki 1982) associated with egg laying (Fig. 4), not the long distance seasonal migrations that population and applied ecologists can consider problematic (e.g. Chapman et al. 2003). Our agents were vagile in the sense that even for high habitat preference values relative to the matrix, they still leave. In fact our preference parameter was best interpreted as a likelihood of leaving a patch. High preference values led to agents concentrating eggs in patches of hosts; $c f$. Roots' resource concentration hypothesis (Root 1972). Butterflies such as the monarch certainly appear to ignore boundaries (Ries \& Debinski 2001) and milkweed patch edges (Zalucki \& Kitching 1982b) and most likely have low preference levels. These patches essentially define the habitat for this species providing oviposition sites, larval food plants, nectar for adults and mating resources (Bull et al.1985; Zalucki \& Kitching 1985; Suzuki \& Zalucki 1986; Zalucki 1993). How far such agents will fly, and necessarily the scale at which the "population" needs to be considered, was a function of landscape features (cover and distribution), relative habitat preference, directionality of movement and step length (Fig. 4). Even for high cover landscapes, movement distances of between 1 and $10 \mathrm{~km}$ mean that most populations would be “open” and not strictly confined to a single patch. For sparse landscapes the movement distances were potentially much greater $(4-20 \mathrm{~km})$ and agree with the 11 km suggested for summer breeding monarchs based on an earlier simulation model (Zalucki 1983). Mark recapture studies suggested such movements were common (Zalucki \& Kitching 1985). In effect a “population” could potentially extend over about $400 \mathrm{~km}^{2}$ making population level studies difficult. Such monarch populations could be best described as "patchy” (sensu Thomas \& Kunin 1999) not as a so-called “metapopulation”.

The time honoured method of counting butterflies around patches of food plant habitat (e.g. Pollard 1977; Kemp \& Zalucki 1999) might estimate numbers in such patches well but will greatly underestimate "population abundance”. Most of the adults in sparse habitat cover landscapes (an average of 50-90\% depending on habitat preference and habitat distribution) will be 'lost' in the space between habitat patches! These adults may or may not be reproducing depending on the availability of hosts in the matrix (Shreeve et al. 2004) (Fig. 6). 
Effects on egg laying: Realized fecundity was greatly influenced by landscape factors, not only by the nature of the matrix, but also by how habitat units are arranged, as well as species-specific attributes of habitat preference, perceptive distance and directionality (Fig. 5). As in Zalucki \& Lammers (2010) the absence of hosts in the matrix can reduce realized fecundity by up to 30\%. Zalucki \& Lammers (2010) modelled movement implicitly as a simple searching function. The important difference with the spatially-explicit model presented here was that we can now predict egg distributions in specific spatial arrangements of patches as they were an emergent property of the model; potentially a testable hypothesis which we leave to a subsequent paper.

The greater the number of habitat patch units, and the more evenly spaced they were, the more likely they were to be encountered and utilized. Clustered landscapes, i.e. where habitats occurred in larger, fewer "fragments", resulted in the lowest realized fecundity. Apart from directionality (high directionality enabling more patches to be encountered) relative habitat preference and perceptive distance are important. Interestingly we know very little about either of these "parameters" for most species.

The search strategies animals use to detect a new habitat when they are 'lost in matrix space’ are not well understood (Bowler \& Benton 2005). Most studies of movement have focused on the likelihood of leaving a habitat or dispersal propensity (e.g. Schultz \& Crone 2001; Berggren et al. 2002; Schtickzelle et al. 2006). The ability of animals to perceive and locate resources as they move through the landscape will contribute not only to dispersal success in fragmented landscapes, namely finding habitat units (e.g. Merckx \& Van Dyck 2007), but also their ability to survive and potentially reproduce in the space or matrix between "habitat” patches (above). Empirical information on the perceptual abilities of animals in real landscapes is limited (Zollner \& Lima 1999; Schooley \& Wiens 2003; Merckx \& Van Dyck 2007). We know from behavioural and electrophysiological studies that insects can perceive resources, such as host plants, from a distance using odour cues and responding accordingly (e.g. Finch \& Collier 2000). But we have few good estimates of perception distance for host plants although these seem to be of the order of tens of metres (Cardé \& Willis 2008), so our values are likely to be close to correct. These perceptions may be disrupted by many factors and so lead to better or worse 
localization of resources (Floater \& Zalucki 2000; Cardé \& Willis 2008). Landscape structure or the nature of the matrix (available resources, physical texture), will also have a direct effect on the movement behaviour of animals; e.g. grass-cover permeability (Wiens et al. 1997), landscape type (Russell et al. 2003), amount of food present (Wallin \& Ekbom 1994).

In our simulations all resources (hosts, nectar sources, roosting sites) were available in each habitat unit. Should these be heterogeneously distributed requiring additional searching movements then realized fecundity will be greatly reduced, as posited by Kitching (1972) for blowflies in “Time, space and population dynamics”.

For monarchs the suggestion is that realised fecundity has been greatly curtailed due to cleansing of the matrix of host plants. Certainly there has been a sustained reduction in the size of the overwintering population in Mexico since the advent of Roundup Ready crops. The decline does not seem to contain a strong climate change signal (Zalucki et al. 2015), which is often posited as a cause of species decline (e.g. Warren et al. 2005).

Conservation: does one size fit all?

Species conservation planning often involves setting aside areas of suitable habitat. Assuming it is not just one large remnant (in which case it should be larger than the "trivial" foraging distance at least), then how these are best arranged will depend very much on the biology of the species in question. It is unlikely one arrangement of fragments will equally suit the requirements of all species utilizing such remnant habitats. As the range of results from the simulation model for different combination of movement parameters within one landscape suggest, one size will not fit all. At a minimum we would need to estimate habitat preference (the propensity to leave), directionality of movement in the space between habitats (the matrix) and how rapidly animals move (step length) as well as perception distance. These would enable better interpretation of data from counts that are almost always undertaken in areas of "habitat". As our simulations suggest for some types of animals most of the adult population will be located away from habitat patches. Putting sentinel plants in nonhabitat areas will quickly determine if there is such a floating population, as these plants will be quickly found and exploited (eggs laid) even if adults are not readily 
seen (see Zalucki \& Kitching 1982a), as local density will be low. We would also predict that species with high preference values would have laid most of their eggs at the end of the day, whereas collections of adults with low preference values from patches would have a binomial distribution, consisting of those that have laid their eggs and a few individuals with many eggs to lay (only just arrived at a patch). Such assessments offer indirect ways of studying movement and egg laying in monarchs, but would require a way of age grading individuals.

Certainly aiding the recovery of monarchs could be influenced by the spatial arrangement of milkweed habitat at a landscape scale. A more uniform distribution of habitat units would appear to be more suitable than a few large clusters far apart. Any addition to landscape cover would be helpful and adding milkweed to roads could well increase realized fecundity. Of course the key question here is would it be sufficient to allow populations to at least replace themselves and persist? That will depend on both the realized fecundity and survival in patches versus single isolated plants in the matrix (Zalucki \& Kitching 1982c). An extension of this simulation modelling approach that includes population dynamics could explore this question in more detail.

\section{Concluding remarks}

Models are essential tools when attempting to understand ecological processes, such as reproduction, at a scale relevant to insect population dynamics. Essentially the conclusion of such modelling follows from the assumptions contained within the model. As McCallum (1995) points out, the leap of faith is that the assumptions adequately describe the 'real' world. The model presented here indicates some credible relationships between the behaviour of monarchs and the likely relative landscape population distribution and realized fecundity: such hypotheses could be tested in the field across a range of landscape types; using a 'model-guided fieldwork' approach sensu Restiff et al. (2012); to see if the emergent patterns suggested by the modelling as a result of underlying processes are valid, thus verifying if our assumptions about these processes are correct. The challenge is to experimentally verify that these agent-based models do in fact capture behaviour and therefore any generated emergent population properties such as "realized" fecundity is in fact realistic. Or alternatively collect sufficient field data observations to compare 
patterns of the model outputs with those expected from the field (the pattern-oriented approach).

\section{Acknowledgments}

To M.P. Zalucki’s PhD supervisor, Roger Kitching, for having the foresight to suggest monarch butterflies were a good model system to study movement and resource use and the temerity to claim everything was known about their biology! We thank Mike Furlong, Cate Paull, Steve Malcolm, Tony Ives for comments and discussion and an anonymous reviewer for comments on the manuscript. 


\section{References:}

Andrewartha H.G. \& Birch L.C. (1954) The distribution and abundance of animals. University of Chicago Press, Chicago, Illinois, USA, 782pp.

Awmack C.S. \& Leather S.R. (2002) Host plant quality and fecundity in herbivorous insects. Annual Review of Entomology 47, 817-844.

Berger D., Walters R. \& Gotthard K. (2008) What limits insect fecundity? Body size- and temperature-dependent egg maturation and oviposition in a butterfly. Functional Ecology 22, 523-529.

Berggren A., Birath B. \& Kindvall 0. (2002) Effect of corridors and habitat edges on dispersal behavior, movement rates, and movement angles in Roesel's bush-cricket (Metrioptera roeseli). Conservation Biology 16, 1562-1569.

Bowler D.E. \& Benton T.G. (2005) Causes and consequences of animal dispersal strategies: relating individual behaviour to spatial dynamics. Biological Reviews 80, 205-225.

Bull C.M., Zalucki M.P., Suzuki Y., Mackay D. \& Kitching R.L. (1985) An experimental investigation of resource use by female monarch butterflies, Danaus plexippus (L.). Australian Journal of Ecology 10, 39198.

Cardé R.T. \& Willis, M.A. (2008) Navigational strategies used by insects to find distant, wind-borne sources of odor. Journal of Chemical Ecology 34, 854866.

Carey J.R. (1989) The multiple decrement life table: a unifying framework for cause-of death analysis in ecology. Oecologia 78, 131-137.

Chapman J.W., Reynolds D.R. \& Smith A.D. (2003) Vertical-Looking Radar: A New Tool for Monitoring High-Altitude Insect Migration. BioScience 53, 503511.

Dempster J.P. (1983) The natural control of populations of butterflies and moths. Biol. Rev. 58, 461-481

Dennis R.L.H. (2004) Butterfly habitats, broad-scale biotope affiliations, and structural exploitation of vegetation at finer scales: the matrix revisited. Ecological Entomology 29, 744-752. 
Dennis R.L.H., Shreeve T.G. \& Van Dyck, H. (2003) Towards a functional resourcebased concept for habitat: a butterfly biology viewpoint. Oikos 102, 417426.

Dennis R.L.H., Hodgson J.G., Grenyer R., Shreeve T.G. \& Roy, D.B. (2004) Host plants and butterfly biology. Do host plant strategies drive butterfly status? Ecological Entomology 29, 1-16.

Dickenson M.H. (2014) Death Valley, Drosophila and the Devonian Toolkit. Annual Review of Entomology 59, 51-72.

Driscoll, D., Banks, S., Barton, P. et al (2013) Conceptual domain of the matrix in fragmented landscapes. Trends in Ecology and Evolution 28, 605-613.

Drielsma, M. \& Ferrier, S. (2009) Rapid evaluation of metapopulation persistence in highly variegated landscapes. Biological Conservation 142, 529-540.

Finch S. \& Collier R.H. (2000) Host-plant selection by insects - a theory based on 'appropriate/inappropriate landings' by pest insects of cruciferous plants. Entomologia Experimentalis et Applicata 96, 91-102.

Fischer S.J., Williams E.H., Brower L.P. \& Palmiotto P.A. (2015) Enhancing monarch butterfly reproduction by mowing fields of common milkweed. American Midand Naturalist (in press).

Fitt G. P., Dillon M. L. \& Hamilton J. G. (1995) Spatial dynamics of Helicoverpa populations in Australia: simulation modelling and empirical studies of adult movement. Computers and Electronics in Agriculture 13, 177-192.

Floater G.J. \& Zalucki M.P. (2000) Habitat structure and egg distributions in the processionary caterpillar Ochrogaster lunifer: lessons for conservation and pest management. Journal of Applied Ecology 37, 87-99.

Gossard T.W. \& Jones R.E. (1977) The effects of agae and weather on egg laying in Pieris rapae L. Journal of Applied Ecology 14, 65-71.

Grimm V. \& Railsback S.F. (2005) Individual-based modeling and ecology. Princeton University Press, Princeton, N.J., pp. 421.

Grimm V., Berger U., Bastiansen F., Eliassen S., Ginot V., Giske J., et al. (2006) A standard protocol for describing individual-based and agent-based models. Ecological Modelling 198, 115-126. doi:

10.1016/j.ecolmodel.2006.04.023 
Grimm V., Berger U., DeAngelis D.L., Polhill J.G., Giske J. \& Railsback S.F. (2010) The ODD protocol: A review and first update. Ecological Modelling 221, 2760-2768. doi: 10.1016/j.ecolmodel.2010.08.019

Hawkes, C. (2009), Linking movement behaviour, dispersal and population processes: is individual variation a key? Journal of Animal Ecology 78, 894-906. doi: 10.1111/j.1365-2656.2009.01534.x

Hiebeler D. (2000) Populations on fragmented landscapes with spatially structured heterogeneities: landscape generation and local dispersal. Ecology 81, 1629-1641.

Jallow M.F.A. \& Zalucki M.P. (1998) Effects of egg load on the host selection behaviour of Helicoverpa armigera (Hübner) (Lepidoptera: Noctuidae). Australian Journal of Zoology 46, 291-299.

Jones R.E. (1977) Movement patterns and the egg distributions of cabbage butterflies. Journal of Animal Ecology 46, 195-212.

Jones R.E., Gilbert N., Guppy M. \& Nealis V. (1980) Long distance movements in Pieris rapae. Journal of Animal Ecology 49, 629-642.

Kemp D.J. \& Zalucki M.P. (1999) Method of handling affects post-capture encounter probabilities in male Hypolimnas bolina (L.) (Nymphalidae). Journal of the Lepidopterists Society 53,138-141.

Kitching R.L. (1971) A simple simulation model of dispersal of animals among units of discrete habitat. Oecologia 7, 95-116.

Kitching R.L. (1977) Time, resources and population dynamics in insects. Australian Journal of Ecology 2, 31-42.

Kitching R.L. \& Zalucki M.P. (1982) Component analysis and modelling of the movement process: analysis of simple tracks. Researches in Population Ecology 24, 224-38.

Leather S.R. (1988) Size, reproductive potential and fecundity in insects - things aren't as simple as they seem. Oikos 51, 386-389.

Logan D.P., Allsopp P.G. \& Zalucki M.P. (2001) Effect of body size on fecudity of Childers canegrub, Antitrogus parvulus Britton (Coleoptera: Scarabaeidae). Australian Journal of Entomology 40, 365-370.

MacFadyen S., Hopkinson J.E., Parry H.R., Neave M.J., Bianchi F.J.J.A., Zalucki M.P. \& Schellhorn N.A. (2015) Early-season crop colonization: movement 
dynamics of pest and natural enemies across a native vegetation-crop ecotone. Agriculture Ecosystems and Environment (in press)

McCallum HI. (1995) Modelling wildlife-parasite interactions to help plan and interpret field studies. Wildlife Research 22, 21-29.

Merckx T. \& Van Dyck H. (2007) Habitat fragmentation affects habitat-finding ability of the speckled wood butterfly, Pararge aegeria L. Animal Behaviour 74, 1029-1037.

Murdie G. \& Hassell M.P. (1973) Food distribution, searching success and predator-prey models. In: M.S. Bartlett \& R.W. Hiorns (eds) The Mathematical Theory of the Dynamics of Biological Populations. London, N.Y., Academic Press, 87-101.

North M. J., Collier N. T., Ozik J., Tatara E., Altaweel M., Macal C. M., et al. (2013) Complex Adaptive Systems Modeling with Repast Simphony. Complex Adaptive Systems Modeling 1, http://www.casmodeling.com/content/1/1/3.

Ovaskainen O. \& Hanski I. (2004) From Individual Behavior to Metapopulation Dynamics: Unifying the Patchy Population and Classic Metapopulation Models. The American Naturalist 164, 364-377.

Parry H.R., Macfadyen S., Hopkinson J.E., Bianchi F.J.J.A., Zalucki M.P., Bourne, A. \& Schellhorn N.A. (2015) Plant composition of non-crop habitat and the abundance of arthropod pests and predators: evidence for culling exotics and planting natives. Basic and Applied Ecology (in press)

Pleasants J.M. \& Oberhauser K.S. (2012) Milkweed loss in agricultural fields because of herbicide use: effect on the monarch butterfly population. Insect Conservation and Diversity 6, 135-144.

Pollard E. (1977) A method for assessing changes in the abundance of butterflies. Biological Conservation 12, 115-134.

Rempel R.S., Kaukinen D. \& Carr A.P. (2012) Patch Analyst and Patch Grid. Ontario, Onatrio Ministry of Natural Resources, Centre for Northern Forest Ecosystem Research.

Restif O., Hayman D. T. S., Pulliam J. R. C., Plowright R. K., George D. B., Luis A. D., et al. (2012). Model-guided fieldwork: practical guidelines for multidisciplinary research on wildlife ecological and epidemiological 
dynamics. Ecology Letters 15, 1083-1094. doi: 10.1111/j.1461-

0248.2012.01836.x

Ries L. \& Debinski D. M. (2001) Butterfly responses tohabitat edges in the highly fragmented prairies of central Iowa. Journal of Animal Ecology 70, 840852.

Roff D.A. (1973) Spatial heterogeneity and the persistence of population. Oecologia 15, 245-258.

Roff D.A. (1975) Population stability and the evolution of dispersal in a heterogeneous environment. Oecologia 19, 217-237.

Root R.B. (1972) Organisation of a plant-arthropod association in simple and diverse habitats: the fauna of collards (Brassica oleracea). Ecological Monographs 43, 95-124.

Roeder K.A. \& Behmer S.T. (2014) Lifetime consequences of food proteincarbohydrate content for an insect herbivore. Functional Ecology 28, 1135-1143.

Russell R.E., Swihart R.K. \& Feng Z. (2003) Population consequences of movement decisions in a patchy landscape. Oikos 103, 142-152.

Sand, D.P.A.S. \& New, T.R. (2002) The Action Plan for Australian Butterflies, Environment Australia, Canberra

Sappington T.W. \& Burks C.S. (2014) Patterns of Flight Behavior and Capacity of Unmated Navel Orangeworm (Lepidoptera: Pyralidae) Adults Related to Age, Gender, and Wing Size. Environmental Entomology 43, 696-705.

Saura S. \& Martínez-Millán J. (2000) Landscape patterns simulation with a modified random clusters method. Landcape Ecology 15, 661-678.

Schellhorn N.A., Pierce S., Bianchi F.J.J.A., Williams D. \& Zalucki, M.P. (2008) Designing landscapes for multiple outcomes in broad-acre environments. Australian Journal of Experimental Agriculture 48, 1549-1559.

Schellhorn N.A., Bianchi F.J.J.A. \& Hsu C.L. (2014) Movement of entomophagous arthropods in agricultural landscapes: links to pest suppression. Annual Review of Entomology 59, 559-581.

Schooley R.L. \& Wiens J.A. (2003) Finding habitat patches and directional connectivity. Oikos 102, 559-570.

Schultz C.B. \& Crone E.E. (2001) Edge-mediated dispersal behavior in a prairie 
butterfly. Ecology 82, 1879-1892.

Schtickzelle N., Mennechez G. \& Baguette M. (2006) Dispersal depression with habitat fragmentation in the bog fritillary butterfly. Ecology 87, 10571065.

Shreeve T.G., Deninis R.L.H. \& Van Dyck H. (2004) Resources, habitats and metapopulations - whither reality? Oikos 106, 404-408.

Stolk H.J., Hanan J. \& Zalucki M.P. (2007) Subpopulation agents emerge from individual agents in metapopulation simulations. In: L. Oxley \& D. Kulasiri (eds) MODSIM 2007 International Congress on Modelling and Simulation. Modelling and Simulation Society of Australia and New Zealand, December 2007, pp. 46-52.

Suzuki, Y. \& Zalucki M.P. (1986) Mate acquisition as a factor influencing female dispersal in Danaus plexippus (L.). Journal of the Australian entomological Society 25, 31-35.

Thomas C.D. \& Kunin W.E. (1999) The spatial structure of populations. Journal of Animal Ecology 68, 647-657.

Wallin H. \& Ekbom B.S. (1994) Influence of hunger level and prey densities on movement patterns in three species of Pterostichus beetles (Coeloptera, Carabidae). Population Ecology 23, 1171-1181.

Walter, G. \& Zalucki, M.P. (1999) Rare Butterflies and Theories of Evolution and Ecology. In: R.L. Kitching, E. Scheermeyer, R.E. Jones and N.E. Pierce (eds). Biology of Australian Butterflies. CSIRO publishing, Melbourne, pp 349368.

Warren M.S., Hill J.K., Thomas J.A., Asher J., Fox R., Huntley B., Roy D.B., Telfer M.G., Jeffcoate S., Harding P., Jeffcoate G., Willis S.G., Greatorex-Davies J.N., Moss D. \& Thomas C.D. (2001) Rapid responses of British butterflies to opposing forces of climate and habitat change. Nature 414, 65-69.

Westerberg, L. \& Wennergren, U. (2003) Predicting the spatial distribution of a population in a heterogeneous landscape. Ecological Modelling 166, 5365. 
Wiens J.A., Schooley R.L. \& Weeks R.D. Jr. (1997) Patchy landscapes and animal movements: do beetles percolate? Oikos 78, 257-264.

Zahiri B., Fathipour Y., Khanjani M., Moharramipour S. \& Zalucki, M.P. (2014) Alternatives to key factor analyses for assessing the population dynamics of Hypera postica (Coleoptera: Curculionidae). Population Ecology 56, 185-194.

Zalucki M.P. (1981) The effects of age and weather on egg laying in Danaus plexippus L. (Lepidoptera: Danaidae). Researches in Population Ecology 23, 318-27.

Zalucki M. P. (1983) Simulation of movement and egglaying in Danus plexippus (Lepidoptera: nymphalidae). Research in Population Ecology 25, 353-365.

Zalucki M.P. (1993) Sex around the milkweed patch - the significance of patches of host plants in monarch reproduction. In: S.B. Malcolm \& M.P. Zalucki (eds.) The Biology and Conservation of the Monarch Butterfly, pp. ??, Los Angeles Museum of Natural History Contributions to Science, Los Angeles, USA.

Zalucki M.P. \& Kitching R.L. (1982a) The dynamics of oviposition of Danaus plexippus L. on Asclepias spp. Journal of Zoology, London 198, 103-16. Zalucki M.P. \& Kitching R.L. (1982b) Movement pattern in Danaus plexippus L. Behaviour 80, 174-98.

Zalucki M.P. \& Kitching R.L. (1982c.) Temporal and spatial variation of mortality in field population of Danaus plexippus and D. chrysippus L. larvae (Lepidoptera: Nymphalidae). Oecologia 53, 201-07.

Zalucki M.P. \& Kitching R.L. (1985) The dynamics of adult Danaus plexippus L. around patches of its host plant Asclepias spp. Journal of the Lepidopterists Society 38, 209-19.

Zalucki M.P. \& Lammers J. H. (2010) Dispersal and egg shortfall in Monarch butterflies: what happens when the matrix is cleaned up? Ecological Entomology 35, 84-91.

Zalucki M.P., Chandica A. \& Kitching R.L. (1981) Quantifying the distribution and abundance of an animal's resource using aerial photography. Oecologia 50, $176-83$. 
Zalucki, M. P., Murray, D. A. H., Gregg, P. C., Fitt, G. P., Twine, P. H., \& Jones, C. (1986). Ecology of Helicoverpa armigera (Hubner) and Heliothis punctigera (Wallengren) in Australia - What do we know? Australian Journal of Zoology 34, 779-814.

Zalucki M.P., Brower L.P., Malcolm S.B \& Slager B.H. 2015. Estimating the climate signal in monarch population decline: no direct evidence for climate change? In: K.S. Oberhauser, K. Nail, and S. Altizer (eds.) Monarchs in a changing world: biology and conservation of an iconic insect, pp. ?? Cornell Univ. Press: Ithaca, NY.

Zollner P.A. \& Lima S.L. (1999) Search-strategies for landscape-level interpatch movements. Ecology 80, 1019-1030. 